\title{
Hyperhomocysteinemia and MTHFR gene 677 C>T polymorphism: questionable role in female infertility
}

\author{
Vinita Das, Devyani Misra*, Smriti Agrawal, Anjoo Agrawal, Amita Pandey
}

Department of Obstetrics \& Gynecology, King George's Medical University, Lucknow-226003, U.P., India

Received: 18 March 2015

Accepted: 19 April 2015

\author{
*Correspondence: \\ Dr. Devyani Misra, \\ E-mail: dr.devyanimisra@gmail.com
}

Copyright: $\odot$ the author(s), publisher and licensee Medip Academy. This is an open-access article distributed under the terms of the Creative Commons Attribution Non-Commercial License, which permits unrestricted non-commercial use, distribution, and reproduction in any medium, provided the original work is properly cited.

\begin{abstract}
Background: Homocysteine is an intermediate in methionine metabolism required for the biosynthesis of nucleic acids. Hyperhomocysteinemia affects various organ systems and also has been implicated as a risk factor for infertility. Elevated levels result either from genetic mutations of the enzymes catalyzing the metabolic pathway or deficiency of micronutrients required as co-enzymes for the same. The aim of this cohort study was to evaluate serum homocysteine levels and MTHFR gene 677C $>\mathrm{T}$ mutation and to establish a possible relation between hyperhomocysteinemia, genetic polymorphism and female infertility.

Methods: Ninety-five infertile women were enrolled over a period of one year and categorized as unexplained, anovulatory and male partner factor infertility according to the etiology. Thirty-one age-matched fertile women were enrolled as controls. Serum homocysteine levels were evaluated and genetic analysis for MTHFR gene mutation $677 \mathrm{C}>\mathrm{T}$ was done.

Results: Mean homocysteine levels for the women in three infertile groups were comparable (group I - $16.21 \pm 3.39$ $\mu \mathrm{mol} / \mathrm{l}$, group II $-16.36 \pm 3.56 \mu \mathrm{mol} / \mathrm{l}$, group III $-16.98 \pm 3.14 \mu \mathrm{mol} / \mathrm{l}$ ) within the groups as well as with the fertile group $(15.85 \pm 9.3 \mu \mathrm{mol} / \mathrm{l})$ with no statistically significant difference $(\mathrm{P}=0.573)$. Prevalence of hyperhomocysteinemia was $86.3 \%$ for infertile group and $90.3 \%$ for fertile group. Nineteen heterozygous (CT) and 3 homozygous (TT) mutations were noted among infertile subjects and 8 heterozygous (CT) mutations among fertile subjects prevalence being similar for both the groups.

Conclusions: Significant prevalence of hyperhomocysteinemia and MTHFR polymorphism was observed in the studied population. The study did not establish a positive role of hyperhomocysteinemia and MTHFR mutation in female infertility.
\end{abstract}

Keywords: Female infertility, Hyperhomocysteinemia, MTHFR 677 C $>$ T polymorphism

\section{INTRODUCTION}

Methionine is an amino acid essential for nucleic acid biosynthesis. Homocysteine is an important intermediate in methionine metabolism involving the enzyme methylenetetrahydrofolate reductase (MTHFR). Accumulation of homocysteine may result from a deficiency of vitamins involved in its metabolism (vitamin $\mathrm{B}_{6}, \mathrm{~B}_{12}$, folic acid) or a mutation of genes encoding the enzyme methylenetetrahydrofolate reductase. Hyperhomocysteinemia is a known risk factor for atherosclerosis, ${ }^{1}$ cardiovascular diseases, ${ }^{2}$ stroke, ${ }^{3}$ peripheral venous thrombosis ${ }^{4}$ and neurodegenerative disease. ${ }^{5}$ In pregnancy, it is postulated to be a risk factor for adverse outcomes like early pregnancy loss, ${ }^{6}$ neural tube defects, ${ }^{7}$ preeclampsia, ${ }^{8}$ abruptio placenta ${ }^{9}$ and intrauterine growth restriction. ${ }^{10}$

Hyperhomocysteinemia has also been implicated as a factor for infertility. It is believed that hyperhomocysteinemia causes defective follicular 
development, oxidative damage to oocyte membrane, impairs chorionic villus vascularization, causes implantation failure and alters intrauterine milieu making it non-conducive for fertilization or implantation. ${ }^{11,12}$ The follicular fluid homocysteine level is a reflection of systemic homocysteine metabolism. ${ }^{13}$ Studies of follicular fluid in women undergoing assisted reproduction suggest an inverse association between follicular fluid homocysteine levels and oocyte and embryo quality. ${ }^{14,15}$ Increased plasma and follicular homocysteine levels negatively correlate with oocyte maturation leading to a number of development defects of the oocyte that impede fertilization and/or the reproductive outcome in polycystic ovarian syndrome (PCOS) patients undergoing assisted reproduction. ${ }^{16,17}$

Hence, this study was planned to evaluate serum homocysteine levels, prevalence of MTHFR polymorphism in infertile women and to evaluate the role $\begin{array}{llll}\text { of hyperhomocysteinemia and MTHFR } 677 & \mathrm{C}>\mathrm{T}\end{array}$ mutation in female infertility.

\section{METHODS}

This study was conducted in the department of Obstetrics and Gynecology of King George's Medical University (KGMU), Lucknow, over a period of 1 year, from September 2011 to August 2012 after approval by the institutional ethics committee. Women attending the Infertility Clinic at the department were enrolled. After taking informed consent a predesigned questionnaire was filled by the subjects including age, area of residence, dietary habits, parity, menstrual and obstetric history and type of infertility. A note was made regarding blood sugar levels, height and weight of the subjects and Body Mass Index. Important investigations like male partner's semen analysis, tubal patency tests/laparoscopic chromopertubation findings, serum levels of ThyroidStimulating Hormone, Prolactin, Follicle-stimulating Hormone and Luteinizing Hormone and pelvic ultrasound for polycystic ovaries were also documented. Ninety five infertile and 31 fertile women were enrolled for the purpose of this study. The samples were analyzed at Endocrinology department of Central Drug Research Institute (CDRI), Lucknow.

The subjects were categorized into groups depending on the cause of infertility as follows:

Group I - 33 women with unexplained infertility (women with normal hormonal profile, normal uterine cavity and patent tubes proven by HSG or laparoscopy, regular menstrual cycles, no evidence of endometriosis and normal semen parameters of male partner as per WHO 2010 criteria)

Group II - 31 women with anovulatory infertility (oligomenorrhoea (i.e. prolonged menstrual cycles), ultrasonogram documented anovulation, women with
Polycystic Ovarian Syndrome as per Rotterdam criteria (2007))

Group III - 31 women with male partner infertility (as per World Health Organization 2010 criteria of normal semen parameters)

Controls - 31 age matched fertile women with one or more successful pregnancy and without any history of gestational complications like recurrent abortions, preeclampsia or still births.

\section{Inclusion criteria}

- $\quad$ Age- 25 to 40 years

- Unilateral or bilateral patent tubes on hysterosalpingography or laparoscopy

- Women willing to participate in the study

\section{Exclusion criteria}

- Known case of endometriosis or fibroid

- Pelvic Inflammatory Disease

- Women not consenting for the study

Five $\mathrm{ml}$ of venous blood was drawn from each subject, 2 $\mathrm{ml}$ was collected in ethylenediaminetetraacetic acid vials and $3 \mathrm{ml}$ in serum vials. The serum vials were centrifuged within 1 hour of collection in 'Spermfuge' at $2000 \mathrm{rpm}$, stored at 4 degree Centigrade and transported to CDRI at the earliest possible maintaining a proper cold chain. At CDRI, the serum vials were analyzed for homocysteine levels using the principle of adsorption with the decrease in adsorbance value of the sample at $340 \mathrm{~nm}$ due to oxidation of $\mathrm{NADH}$ to $\mathrm{NAD}^{+}$(Globe Diagnostics).

The EDTA vial samples were used for genetic study. Point mutation $(677 \mathrm{C}>\mathrm{T})$ in the MTHFR gene was typed using direct DNA sequencing technique. Primers around the polymorphic site were designed with the help of GENETOOL software. PCR was carried out using Taq DNA polymerase enzyme in ABI Veriti thermal cycler (Applied Biosystems, USA). The amplified products were directly sequenced using BigDyeTM chain termination chemistry on ABI 3730 DNA analyzer followed by multiple alignment and sequence analysis using Auto Assembler Software (Applied Biosystems, USA).

The statistical analysis was done using SPSS (Statistical Package for Social Sciences) Version 15.0 statistical Analysis Software. Mean value for serum homocysteine was determined along with standard deviation. The characteristics of the patients and the mean plasma 
homocysteine concentrations between the infertile groups and fertile group were compared by Student's t test for unpaired data and between and within the different groups with the ANOVA. Allelic and genotypic frequencies were determined from observed genotype counts and differences in the genotype distribution between different groups were assessed by Pearson's $\chi^{2}$ test of heterogeneity. Pearson correlation coefficient $<0.05$ was considered significant. Hardy Weinberg law of genetic equilibrium could not be evaluated due to small number of subjects included.

\section{RESULTS}

The subjects in the three infertile groups were comparable with each other as well as with the fertile group with respect to demographic parameters as depicted in Table 1.

Table 1: Demographic characteristics - Infertile and fertile groups.

\begin{tabular}{|llllll|} 
Parameter & Group I $(\mathbf{n}=\mathbf{3 3})$ & Group II $(\mathrm{n}=\mathbf{3 1})$ & Group III $(\mathbf{n = 3 1})$ & $\begin{array}{l}\text { Fertile group } \\
(\mathrm{n}=\mathbf{3 1})\end{array}$ & df \\
\hline Mean age $\pm \mathrm{SD}(\mathrm{years})$ & $30.09 \pm 3.61$ & $28.39 \pm 4.94$ & $29.32 \pm 4.24$ & $30.97 \pm 4.03$ & $\mathrm{~F}=2.107 ; \mathrm{P}=0.103$ \\
\hline Mean BMI $\pm \mathrm{SD}\left(\mathrm{kg} / \mathrm{m}^{2}\right)$ & $23.56 \pm 3.36$ & $24.45 \pm 4.76$ & $24.60 \pm 4.35$ & $24.02 \pm 3.15$ & $\mathrm{~F}=0.450 ; \mathrm{P}=0.718$ \\
\hline Residence rural & $10(30.3 \%)$ & $15(48.4 \%)$ & $8(25.8 \%)$ & $8(25.8 \%)$ & $\chi^{2}=4.902 ; \mathrm{P}=0.179$ \\
\hline Vegetarian diet & $29(87.9 \%)$ & $19(61.3 \%)$ & $19(61.3 \%)$ & $25(80.6 \%)$ & $\chi^{2}=8.942(\mathrm{df}=3) ; \mathrm{P}=0.030^{\mathrm{a}}$ \\
\hline
\end{tabular}

$* \mathrm{P}<0.05$ as compared to control (t-test)

a - Significant difference in vegetarians between the infertile and fertile groups

The mean age of subjects in group II was slightly less when compared with the other infertile groups or when compared with the fertile group. Also significant was the higher percentage of vegetarians in group I as well as the fertile group. Group II had 18 cases of PCOS diagnosed on USG.

Serum homocysteine levels are normally in the range of 4 to $12 \mu \mathrm{mol} / \mathrm{l}^{18}$ Levels higher than $12 \mu \mathrm{mol} / \mathrm{l}$ are considered as hyperhomocysteinemia. In the present study, the mean serum homocysteine level was $16.21 \pm$ $3.39 \mu \mathrm{mol} / \mathrm{l}, 16.36 \pm 3.56 \mu \mathrm{mol} / 1,16.98 \pm 3.14 \mu \mathrm{mol} / \mathrm{l}$ for groups I, II and III respectively. For the fertile group, the mean serum homocysteine was $15.85 \pm 2.63 \mu \mathrm{mol} / \mathrm{l}$. The homocysteine levels were comparable for the study groups and difference with the fertile group was not statistically significant $(\mathrm{F}=0.669 ; \mathrm{P}=0.573)$. Eighteen cases of PCOS included in group II had a mean serum homocysteine level of $16.88 \pm 3.10 \mu \mathrm{mol} / \mathrm{l}$ which was not statistically different from homocysteine levels of other women in group II $(16.02 \pm 3.62 \mu \mathrm{mol} / \mathrm{l})$ or women included in group I, III and the controls.

The prevalence of hyperhomocysteinemia among infertile and fertile subjects is depicted in Table 2. The prevalence of hyperhomocysteinemia was similar for the infertile groups as well as the fertile group.

Table 2: Prevalence of hyperhomocysteinemia - Infertile and fertile groups.

\begin{tabular}{|c|c|c|c|c|c|c|c|c|}
\hline \multirow[t]{2}{*}{ Homocysteine levels } & \multicolumn{2}{|c|}{ Group I (n=33) } & \multicolumn{2}{|c|}{ Group II (n=31) } & \multicolumn{2}{|c|}{ Group III (n=31) } & \multicolumn{2}{|c|}{$\begin{array}{l}\text { Fertile group } \\
(\mathrm{n}=\mathbf{3 1})\end{array}$} \\
\hline & No. & $\%$ & No. & $\%$ & No. & $\%$ & No. & $\%$ \\
\hline Hyper-homocysteine (SHCy >12 $\mu \mathrm{mol} / \mathrm{L}$ ) & 28 & 84.8 & 27 & 87.1 & 27 & 87.1 & 28 & 90.3 \\
\hline Normal homocysteine $(\mathrm{SHcy}=4-12 \mu \mathrm{mol} / \mathrm{L})$ & 5 & 15.2 & 4 & 12.9 & 4 & 12.9 & 3 & 9.7 \\
\hline Statistical significance & \multicolumn{2}{|c|}{$\chi^{2}=0.438 ; P=0.508$} & \multicolumn{2}{|c|}{$\chi^{2}=0.161 ; P=0.688$} & \multicolumn{2}{|c|}{$\chi^{2}=0.161 ; P=0.688$} & \multicolumn{2}{|c|}{$\mathrm{P}=0.884$} \\
\hline
\end{tabular}

Table 3: Prevalence of vegetarian diet among infertile and fertile subjects with hyperhomocysteinemia.

\begin{tabular}{|ll|}
\hline $\begin{array}{l}\text { Subjects with } \\
\text { hyperhomocysteinemia }\end{array}$ & $\begin{array}{l}\text { Vegetarian dietary } \\
\text { preference }\end{array}$ \\
\hline Infertile subjects $(\mathrm{n}=67 / 95)$ & $56 / 67(83.6 \%)$ \\
\hline Fertile subjects $(\mathrm{n}=25 / 31)$ & $22 / 25(88.0 \%)$ \\
\hline
\end{tabular}

MTHFR gene mutation $677 \mathrm{C}>\mathrm{T}$ involves replacement of Cytosine by Thymine at position 677 of the gene resulting in a base change from alanine to valine at position 222 of the enzyme reducing its activity leading to hyperhomocysteinemia. ${ }^{19}$ There were 19 cases $(20.4 \%)$ of heterozygous MTHFR mutation CT among the 
infertile groups and $8(25.8 \%)$ among the fertile group. Three cases $(3.2 \%)$ of homozygous MTHFR mutation TT were reported among the infertile group whereas there were none among the fertile subjects. Statistical analysis revealed no significant difference in prevalence of mutations among the various infertile groups or the fertile subjects $\left(\chi^{2}=4.171 ;(\mathrm{df}=6) ; \mathrm{P}=0.654\right)$.

Table 4: Incidence of MTHFR gene mutation in subjects with hyperhomocysteinemia - Infertile and fertile groups.

\begin{tabular}{|c|c|c|c|c|c|}
\hline $\begin{array}{l}\text { MTHFR gene mutation in subjects } \\
\text { with hyperhomocysteinemia }\end{array}$ & $\begin{array}{l}\text { Group I } \\
(\mathrm{n}=\mathbf{2 8})\end{array}$ & $\begin{array}{l}\text { Group II } \\
(\mathbf{n}=27)\end{array}$ & $\begin{array}{l}\text { Group III } \\
(\mathrm{n}=27)\end{array}$ & $\begin{array}{l}\text { Fertile group } \\
(\mathrm{n}=\mathbf{2 8})\end{array}$ & Significance \\
\hline TT (homozygous MTHFR variant) & $2(7.1 \%)$ & 0 & 0 & 0 & \multirow{2}{*}{$\begin{array}{l}\chi^{2}=5.590 \\
P=0.133\end{array}$} \\
\hline CT (heterozygous MTHFR variant) & $5(17.8 \%)$ & $7(25.9 \%)$ & $5(18.5 \%)$ & $6(21.4 \%)$ & \\
\hline
\end{tabular}

\section{DISCUSSION}

Subjects in the three infertile and the fertile groups in the present study were comparable with respect to demographic characteristics and hemodynamic parameters.

Of significance was the lower mean age $(\mathrm{P}<0.05)$ of females in group II compared with the other groups or the controls. This could be explained due to the fact that women in the anovulatory group presented earlier to infertility clinic due to associated menstrual irregularities.

Also, the higher percentage of vegetarians in group I and the infertile group was significant. Vegetarian diet is known to be deficient in vitamin $\mathrm{B}_{12}$, an important coenzyme in the methionine pathway. Its deficiency therefore can lead to hyperhomocysteinemia. However, in the present study, the prevalence of hyperhomocysteinemia was similar for all the groups irrespective of the dietary preferences. Vice-versa, among the subjects with hyperhomocysteinemia, the study did not reveal any significant difference in dietary preference. Table 3 represents the prevalence of vegetarian dietary preference among the subjects with hyperhomocysteinemia in the present study.

The study shows a very high prevalence of hyperhomocysteinemia in all the groups included. The prevalence of hyperhomocysteinemia was similar among the infertile groups and also when compared with the fertile subjects. Levels of serum homocysteine were also comparable for PCOS and non-PCOS women. The mean level of homocysteine for infertile women was around $16 \mu \mathrm{mol} / 1$ for all the infertile groups. The levels were lower in the fertile group but nevertheless comparable. Since there was no statistically significant difference in homocysteine levels or prevalence of hyperhomocysteinemia between the infertile and fertile groups, no positive association could be established between hyperhomocysteinemia and female infertility.

The prevalence of homozygous and heterozygous mutation between the various infertile groups and fertile subjects were comparable. Heterozygous mutation of MTHFR enzyme results in $35 \%$ decrease and homozygous mutation causes a $70 \%$ reduction in enzyme activity. ${ }^{19}$ Reduced enzyme activity impairs metabolism of folate intermediates leading to hyperhomocysteinemia. Of the subjects with hyperhomocysteinemia, 2 had homozygous MTHFR mutation and both belonged to group I. Heterozygous MTHFR mutation was present in 5,7 and 5 subjects with hyperhomocysteinemia in the three infertile groups respectively. There were 6 cases of heterozygous MTHFR mutation among the fertile subjects (Table 4). No statistically significant difference was observed in the prevalence of MTHFR mutations in infertile and fertile subjects with hyperhomocysteinemia. MTHFR mutation is a known cause for hyperhomocysteinemia which is believed to result in infertility. However, since the prevalence of MTHFR polymorphism was similar for the infertile groups and fertile controls, a positive role of this mutation in causing female infertility could not be established.

The study of Dubey et al. ${ }^{20}$ conducted in a North India population with 30 cases of unexplained infertility and equal controls showed levels of serum homocysteine to be similar to the present study for the infertile group (17.27 $\mu \mathrm{mol} / \mathrm{l})$ but lower for fertile group $(10.87 \mu \mathrm{mol} / \mathrm{l})$. The study showed positive association between hyperhomocysteinemia and female infertility which was contrary to the present study.

A positive correlation between hyperhomocysteinemia and unexplained female infertility was also found in a study by Maristella D'Uva et al. ${ }^{21}$ in a South Italian population which included 20 women with recurrent pregnancy loss, 20 with unexplained sterility and 20 healthy women controls. The mean serum homocysteine value in recurrent pregnancy loss group was $19.2 \mu \mathrm{mol} / \mathrm{l}$, for the infertile group was $21.05 \mu \mathrm{mol} / \mathrm{l}$ and that for controls was $7.85 \mu \mathrm{mol} / 1$. These values were higher for cases and lower for controls when compared with the present study. Heterozygous MTHFR mutation was noted in $5 / 20(25 \%)$ with unexplained infertility, 3/20 (15\%) with recurrent loss and $9 / 20(45 \%)$ controls. The homozygous MTHFR mutant was present in 15/20 (75\%) with unexplained infertility, 17/20 (85\%) with recurrent loss and 3/20 (15\%) among controls. 
Another study by Seema bibi et al. ${ }^{22}$ in Pakistan showed that women suffering from unexplained subfertility had significantly higher homocysteine levels $(12.8 \mu \mathrm{mol} / \mathrm{l})$ as compared to controls $(9.7 \mu \mathrm{mol} / \mathrm{l})$. The authors concluded that hyperhomocysteinemia was positively associated with unexplained female subfertility. The same was not observed in the present study. Similarly, an inverse association between elevated homocysteine levels and fertility outcome was also established by the Dutch study of IMW Ebisch et al. ${ }^{23}$ which evaluated follicular homocysteine levels (Fertile - $14.7 \mathrm{nmol} / \mathrm{mg}$ protein, idiopathic subfertility $-9.2 \mathrm{nmol} / \mathrm{mg}$ protein, tubal factor$9.8 \mathrm{nmol} / \mathrm{mg}$ protein, endometriosis - $18.8 \mathrm{nmol} / \mathrm{mg}$ protein). As mentioned earlier, follicular fluid concentration of homocysteine is a reflection of systemic levels. The present study however did not show any similar results.

Similar to our study, Francesco Oreo Jr et al. ${ }^{24}$ evaluated 70 women with PCOS and 70 healthy women in an Italian population for homocysteine levels and MTHFR polymorphism. The mean homocysteine levels were 11.3 $\mu \mathrm{mol} / \mathrm{l}$ for the PCOS group and $12.2 \mu \mathrm{mol} / \mathrm{l}$ for controls, the difference being insignificant. Also, no difference was observed among cases and controls with respect to MTHFR prevalence although the prevalence of mutation was much higher than the present study (CT - 58.5\% PCOS, $54.3 \%$ controls; TT - $18.6 \%$ PCOS and $21.4 \%$ controls). The study showed positive correlation between MTHFR mutation and raised homocysteine levels in healthy females but not for the women with PCOS. Considering the different MTHFR polymorphisms, no significant difference was observed in serum homocysteine levels between PCOS and controls. Insulin resistance was suggested to play a role in altering homocysteine metabolism only in PCOS without MTHFR polymorphism. Similarly Sills ES et al. ${ }^{25}$ did not find a positive association between homocysteine levels and infertility in PCOS $(n=54)$ in an American population and the levels were within the cut-off levels for both the cases as well as the fertile controls $(n=18)(7 \mu \mathrm{mol} / 1$ for both groups).

On the other hand, Morey Schacter et al. ${ }^{26}$ in the phenomenal Israeli study on 155 infertile PCOS and 100 normally ovulating women with infertility evaluated serum homocysteine levels found mean plasma homocysteine in the PCOS group to be significantly higher than in the normal ovulation group (11.5 vs. 7.4 $\mu \mathrm{mol} / \mathrm{l}, \mathrm{P}<0.001)$ and the levels were even higher in PCOS with insulin resistance. The study suggested that PCOS had other vascular-endothelial factors in addition to hyperhomocysteinemia that mandate evaluation, nevertheless, treatment of hyperhomocysteinemia improved conception and pregnancy outcomes in these women. Insulin resistance was proposed to affect serum homocysteine levels in PCOS. The present study found similar homocysteine levels in PCOS as well non-PCOS and controls.
The Indian study by Madhu Jain et al. ${ }^{27}$ in 92 PCOS and 95 age matched controls for MTHFR polymorphism found a slightly higher prevalence of MTHFR heterozygous mutation in the cases $(17.39 \%)$ when compared with the controls (13.68\%) (OR-1.32). The percentage prevalence was however lower than the present study. The authors documented a higher, although statistically insignificant prevalence of heterozygous MTHFR polymorphism in PCOS along with an increased susceptibility for hyperlipidemia in presence of MTHFR polymorphism.

The present study shows a very high prevalence of hyperhomocysteinemia in subjects in infertile as well as the fertile groups. A major contribution could be attributed to the prevalence of vegetarian diet in this study as most of the subjects enrolled were vegetarians (83.6\% of infertile subjects and $88.0 \%$ fertile subjects with hyperhomocysteinemia were vegetarians in the present study). Indian diet which comprises mainly of vegetarian dietary habits is poor in vitamin $B_{12}$ and other micronutrients which contribute significantly to the development of hyperhomocysteinemia. Thus, dietary factors appear to be significant in causing hyperhomocysteinemia. However, a definite role of hyperhomocysteinemia in causing female infertility was not established.

This study also demonstrates a significant prevalence of MTHFR mutation which may be responsible for hyperhomocysteinemia. However, analysis revealed high levels of homocysteine even in subjects with normal variant of MTHFR. Therefore, a positive association between MTHFR gene $677 \mathrm{C}>\mathrm{T}$ polymorphism and female infertility could not be substantiated in this analysis.

Thus, though diet largely and genetic factors in part appear to be responsible for hyperhomocysteinemia, the etiology for a significant portion remains obscure. Hyperhomocysteinemia appears to be endemic in this part of the country as is evident from the extremely high prevalence. In this setting of endemic hyperhomocysteinemia, a correlation was not found between elevated homocysteine levels, MTHFR polymorphism and female infertility. There are views both in agreement with and against this result as discussed earlier and a definite role in causing female infertility is questionable.

This study has been conducted in a limited number of subjects therefore the results cannot be extrapolated to a larger population. Nevertheless, the trends of hyperhomocysteinemia have been similar to prior studies in the Indian subcontinent. A larger study is therefore needed to confirm and validate the findings in this study and help resolve issues related to hyperhomocysteinemia and infertility. 


\section{ACKNOWLEDGEMENTS}

The authors thank the Endocrinology department of CDRI, Lucknow, India for their support in this study.

Funding: No funding sources

Conflict of interest: None declared

Ethical approval: The study was approved by the institutional ethics committee

\section{REFERENCES}

1. Refsum H, Ueland PM, Nygård O, Vollset SE. Homocysteine and cardiovascular disease. Annu Rev Med. 1998;49:31-62.

2. Dwivedi MK, Tripathi AK, Shukla S, Khan S, Chauhan UK. Homocysteine and cardiovascular disease. Biotechnol Molecul Biol Rev. 2011 May;6(5):101-7.

3. Narayan D, Kaul S, Ravishankar K, Suryaprabha T, Bandaru VC, Mridula KR, et al. Risk factors, clinical profile, and long-term outcome of 428 patients of cerebral sinus venous thrombosis: insights from Nizam's Institute Venous Stroke Registry, Hyderabad (India). Nurol India. 2012 MarApr;60(2):154-9.

4. Bertsch T, Mielke O, Höly S, Zimmer W, Casarin W, Aufenanger J, et al. Homocysteine in cerebrovascular disease: An independent risk factor for subcortical vascular encephalopathy. Clin Chem Lab Med. 2001 Aug;39:721-4.

5. Sudha Seshadri, Alexa Beiser, Jacob Selhub, Jacques PF, Rosenberg IH, D'Agostino RB, et al. Plasma homocysteine as a risk factor for dementia and Alzheimer's disease. N Engl J Med. 2002 Feb;346:476-83.

6. Hibbard BN. The role of folic acid in pregnancy with particular reference to anemia, abruption and abortion. J Obstet Gynaecol Br Commonwealth. 1964;71:529-42.

7. Bjorke-Monsen AL, Ueland PM, Schneede J, Vollset SE, Refsum H. Elevated plasma total homocysteine and C677T mutation of methylene tetrahydrofolate reductase gene in patient with spina bifida. QJM Mon J Assoc Phys. 1997;90:593-6.

8. Sorensen TK, Malinow MR, Williams MA, King IB, Luthy DA. Elevated second-trimester serum homocysteine levels and subsequent risk of preeclampsia. Gynecol Obstet Invest. 1999;48:98103.

9. Ray JG, Laskin CA. Folic acid and homocysteine metabolic defects and the risk of placental abruption, pre-eclampsia and spontaneous pregnancy loss: a systematic review. Placenta. 1999 Sep;20(7):519-29.

10. Leeda M, Riyazi N, de Vries JI, Jakobs C, van Geijn HP, Dekker GA. Effects of folic acid and vitamin B6 supplementation on women with hyperhomocysteinemia and a history of preeclampsia or fetal growth restriction. Am J Obstet Gynecol. 1998;179:135-9.
11. Jerzak M, Putowski L, Baranowski W. Homocysteine level in ovarian follicular fluid or serum as a predictor of successful fertilization. Ginekol Pol. 2003 Sep;74(9):949-52.

12. Ocal P, Ersoylu B, Cepni I, Guralp O, Atakul N, Irez $\mathrm{T}$, et al. The association between homocysteine in the follicular fluid with embryo quality and pregnancy rate in assisted reproductive techniques. J Assist Reprod Genet. 2012 Apr;29(4):299-304.

13. Steegers-Theunissen RP, Boers GH, Blom HJ, Trijbels FJ, Eskes TK. Hyperhomocysteinaemia and recurrent spontaneous abortion or abruptio placentace. Lancet. 1992;339:1122-3.

14. Steegers-Theunissen RP, Steegers EA, Thomas CM, Hollanders HM, Peereboom-Stegeman JH, Trijbels FJ, et al. Study on the presence of homocysteine in ovarian follicular fluid. Fertil Steril. 1993;60:100610.

15. Ebisch IMW, Peters WH, Thomas CM, Wetzels AM, Peer PG, Steegers-Theunissen RP. Homocysteine, glutathione and related thiols affect fertility parameters in the (sub) fertile couple. Hum Reprod. 2006;21:1725-33.

16. Bülent Berker, Cemil Kaya, Rusen Aytac, Hakan Satiroglu. Homocysteine concentrations in follicular fluid are associated with poor oocyte and embryo qualities in polycystic ovary syndrome patients undergoing assisted reproduction. Hum Reprod. 2009;24(9):2293-302.

17. Boxmeer JC, Brouns RM, Lindemans J, Steegers EA, Martini E, Macklon NS, et al. Preconception folic acid treatment affects the microenvironment of the maturing oocyte in humans. Fertil Steril. 2008b;89:1766-70.

18. Alexander Krantz, Maryjane Ferraro, Patrick M. Sluss, Kent B. Lewandrowski. Laboratory reference values: case records of the Massachusetts general hospital. N Engl J Med. 2004;351:1548-63.

19. Frosst P, Blom HJ, Milos R, Goyette P, Sheppard CA, Matthews RG, et al. A candidate genetic risk factor for vascular disease: a common mutation in methylenetetrahydrofolate reductase. Nat Genet. 1995; 10:111-3.

20. Dubey P, Gupta N, Dwivedi S, Swaroop N, Lal P, Thawani V. Hyperhomocysteinemia: a risk factor in unexplained infertility. Int $\mathrm{J}$ Reprod Contracept Obstet Gynecol. 2013;2:165-71.

21. Maristella D’Uva, Pierpaolo Di Micco, Ida Strina, Alviggi C, Iannuzzo $\mathrm{M}$, Ranieri $\mathrm{A}$, et al. Hyperhomocysteinemia in women with unexplained sterility or recurrent early pregnancy loss from Southern Italy: a preliminary report. Thromb J. 2007;5:10.

22. Seema Bibi, Mohammad Ali Pir, Roshan Ara Qazi, Misbah Bibi Qureshi. Hyperhomocysteinemia in Pakistani women suffering from unexplained subfertility. Iran J Reprod Med (Spring). 2010;8(2):76-9.

23. Ebisch IMW, Peters WHM, Thomas CMG, Wetzels AMM, Peer PGM, Steegers-Theunissen RPM. 
Homocysteine, glutathione and related thiols affect fertility parameters in the (sub) fertile couple. Hum Reprod. 2006;21(7):1725-33.

24. Francesco Orio Jr, Stefano Palomba, Sebastiano de Biase, Annamaria Colao, Libuse Tauchmanova, Silvia Savastano, et al. Homocysteine Levels and C677T Polymorphism of methylenetetrahydrofolate reductase in women with polycystic ovary syndrome. J Clin Endocrinol Metab. 2003;88(2):673-9.

25. Sills ES, Genton MG, Perloe M, Schattman GL, Bralley JA, Tucker MJ. Plasma homocysteine, fasting insulin, and androgen patterns among women with polycystic ovaries and infertility. J Obstet Gynaecol Res. 2001 Jun;27(3):163-8.
26. Morey Schachter, Arieh Raziel, Shevach Friedler, Deborah Strassburger, Orna Bern, Raphael Ron-El. Insulin resistance in patients with polycystic ovary syndrome is associated with elevated plasma homocysteine. Hum Reprod. 2003;18(4):721-7.

27. Madhu Jain, Priyanka Pandey, Tiwari NK, Shuchi Jain. MTHFR C677T polymorphism is associated with hyperlipidemia in women with polycystic ovary syndrome. J Hum Reprod Sci. 2012 Jan-Apr;5(1):528 .

DOI: $10.18203 / 2320-1770.1 j \mathrm{rcog} 20150074$

Cite this article as: Das V, Misra D, Agrawal S, Agrawal A, Pandey A. Hyperhomocysteinemia and MTHFR gene $677 \mathrm{C}>\mathrm{T}$ polymorphism: questionable role in female infertility. Int $\mathrm{J}$ Reprod Contracept Obstet Gynecol 2015;4:683-9. 